\title{
AMENDMENTS
}

nature

structural \& molecular biology

\section{Author Correction: Fibril structures of diabetes-related amylin variants reveal a basis for surface-templated assembly}

Rodrigo Gallardo (D), Matthew G. ladanza, Yong Xu (D), George R. Heath (D), Richard Foster, Sheena E. Radford (D) and Neil A. Ranson (iD

Correction to: Nature Structural \& Molecular Biology https://doi.org/10.1038/s41594-020-0496-3, published online 14 September 2020. In the version of this article initially published online, in Table 1, the PDB accession code for the S20G 2PF cryo-EM structure was incorrect. The correct accession code is PDB 6ZRQ. The error has been corrected in the print, PDF and HTML versions of the article.

Published online: 9 October 2020

https://doi.org/10.1038/s41594-020-00525-X

(c) The Author(s), under exclusive licence to Springer Nature America, Inc. 2020

\section{Author Correction: Neutralizing nanobodies bind SARS-CoV-2 spike RBD and block interaction with ACE2}

Jiangdong Huo, Audrey Le Bas, Reinis R. Ruza, Helen M. E. Duyvesteyn, Halina Mikolajek, Tomas Malinauskas@, Tiong Kit Tan (1D, Pramila Rijal, Maud Dumoux (D), Philip N. Ward (D), Jingshan Ren, Daming Zhou, Peter J. Harrison, Miriam Weckener, Daniel K. Clare, Vinod K. Vogirala, Julika Radecke, Lucile Moynié, Yuguang Zhao (1D, Javier Gilbert-Jaramillo (1D, Michael L. Knight (D), Julia A. Tree, Karen R. Buttigieg, Naomi Coombes, Michael J. Elmore, Miles W. Carroll, Loic Carrique (1D, Pranav N. M. Shah (1), William James (1), Alain R. Townsend, David I. Stuart (1), Raymond J. Owens and James H. Naismith (1)

Correction to: Nature Structural \& Molecular Biology https://doi.org/10.1038/s41594-020-0469-6, published online 13 July 2020.

In the version of this article initially published, the PDB accession code for the H11-H4-RBD X-ray crystal structure was incorrect. The correct accession code is 6ZBP. The error has been corrected in the HTML and PDF versions of the article.

Published online: 15 October 2020

https://doi.org/10.1038/s41594-020-00527-9

(c) The Author(s), under exclusive licence to Springer Nature America, Inc. 2020

\section{Author Correction: SARS-CoV-2 Nsp1 binds the ribosomal mRNA channel to inhibit translation}

Katharina Schubert (D), Evangelos D. Karousis, Ahmad Jomaa (D), Alain Scaiola (D), Blanca Echeverria, Lukas-Adrian Gurzeler (D), Marc Leibundgut, Volker Thiel (D), Oliver Mühlemann (D) and Nenad Ban (D)

Correction to: Nature Structural \& Molecular Biology https://doi.org/10.1038/s41594-020-0511-8, published online 9 September 2020. In the version of this article initially published, in the Methods section "Preparation of viral 5'-UTR mRNA and reporter RLuc mRNA," the sequence of the first primer (5'-GACTCACTATAGGGCAACTTTAAAATCTGTGTGGCTGTCACT $\left.-3^{\prime}\right)$ of the pair used to amplify the $5^{\prime}$ untranslated region of SARS-CoV-2 genomic mRNA was incorrect. The correct sequence is 5'-GACTCACTATAGGGCATTAAAGGTTTATACCTTCCCAGGTAACAAAC-3'. The error has been corrected in the HTML and PDF versions of the article.

Published online: 20 October 2020

https://doi.org/10.1038/s41594-020-00533-x

(c) The Author(s), under exclusive licence to Springer Nature America, Inc. 2020 